\title{
PENERAPAN REGRESI ZERO INFLATED GENERALIZED POISSON (ZIGP) PADA DATA OVERDISPERSION
}

\author{
Ni Wayan Amanda Dewi Sulistyaningsih ${ }^{1 \S}$, I Komang Gde Sukarsa ${ }^{2}$, Ni Luh Putu Suciptawati ${ }^{3}$ \\ ${ }^{1}$ Program Studi Matematika, Fakultas MIPA - Universitas Udayana [Email: dewiamanda32@gmail.com] \\ ${ }^{2}$ Program Studi Matematika, Fakultas MIPA - Universitas Udayana [Email: gedesukarsa@unud.ac.id] \\ ${ }^{3}$ Program Studi Matematika, Fakultas MIPA - Universitas Udayana [Email: suciptawati@unud.ac.id] \\ ${ }^{\S}$ Corresponding Author
}

\begin{abstract}
Zero Inflated Generalized Poisson (ZIGP) is a regression model used to analyze Poisson distributed discrete data which contains mostly zero and tends to experience overdispersion (varians value greater than the mean value). The purpose of this research is to find out the best model and the factors which influence the maternal mortality in Bali Province in year 2016 by using ZIGP regression model. The data used in this research was data from health profile Bali Province with the object totally 57 district rate data has proportion of zeros value more than $50 \%$ on the response variable. The analysis result of ZIGP data on maternal mortality cannot modeled using the ZIGP so $Z I G P$ regression model became ZIP model. The best model which resulted from ZIP regression got one free variable which have significant impact towards the total number of maternal mortality. This significant variabel is the percentage of mother did visiting to $K l\left(X_{1}\right)$.
\end{abstract}

Keywords: Maternal mortality, Overdispersion, Zero Inflated Generalized Poisson (ZIGP), Zero Inflated Poisson (ZIP).

\section{PENDAHULUAN}

Analisis regresi adalah salah satu model yang digunakan untuk mengetahui hubungan sebab akibat antar variabel, yaitu variabel bebas $(X)$ dengan variabel respons $(Y)$. Variabel respons dan variabel bebas memiliki hubungan yang dapat dinyatakan dalam persamaan matematis yaitu persamaan regresi. Persamaan regresi dapat berbentuk persamaan regresi linear maupun persamaan regresi non-linear. Persamaan regresi linear digunakan untuk menganalisis variabel respons yang berupa peubah acak kontinu dan mengikuti distribusi normal. Namun banyak ditemukan variabel respons yang tidak berdistribusi normal dan tidak linear dalam parameter. Untuk mengatasi hal tersebut dikembangkan generalized linear model (GLM). GLM digunakan sebagai perluasan model regresi umum dengan variabel responsnya berdistribusi keluarga eksponensial, meliputi distribusi normal, binomial, Poisson, binomial negatif, eksponensial, gamma, dan invers normal (Myers et al.,2010).

Regresi Poisson digunakan apabila variabel respons adalah peubah acak diskret. Analisis data menggunakan model regresi Poisson harus memenuhi asumsi seperti nilai varians sama dengan rata-rata dari variabel respons tersebut atau equidispersi (Myers et al., 2010). Namun, dalam kenyataannya sering terjadi pelanggaran asumsi tersebut, yaitu nilai variansnya lebih besar dari nilai rata-rata yang dinamakan overdispersi. Overdispersi pada regresi Poisson dapat dilihat dari nilai taksiran dispersi yaitu nilai devians dan pearson chi square dibagi dengan derajat bebasnya bernilai lebih besar dari satu. Jika terjadi overdispersi pada data, maka regresi Poisson kurang akurat digunakan untuk analisis karena akan berdampak pada nilai standard error menjadi lebih kecil dari nilai sesungguhnya (underestimate), sehingga kesimpulan yang diperoleh menjadi tidak valid (McCullagh \& Nelder, 1989). 
Salah satu penyebab terjadinya overdispersi yaitu adanya nilai nol yang berlebih pada variabel respon (excess zeros). Untuk mengatasi masalah overdispersi tersebut dapat digunakan beberapa model regresi antara lain model regresi zero inflated poisson (ZIP) dengan proporsi nol sekitar $63,7 \%$, dan zero inflated generalized poisson (ZIGP) dengan proporsi nol 65,7\%. Model regresi zero inflated generalized poisson (ZIGP) merupakan perluasan dari model regresi Poisson dan merupakan gabungan dari model regresi zero inflated poisson (ZIP) dan model regresi generalized poisson (GP) (Famoye dan Singh, 2006).

Studi kasus yang digunakan pada penelitian ini adalah Angka Kematian Ibu Hamil di Provinsi Bali tahun 2016. Data menunjukkan terjadi peristiwa kematian ibu hamil tahun 2016 sebanyak 18 ibu di 57 Kecamatan (Dinas Kesehatan Provinsi Bali, 2016). Tujuan dari penelitian ini adalah untuk menentukan model terbaik ZIGP serta untuk mengetahui faktorfaktor yang mempengaruhi kematian ibu hamil.

Secara umum model regresi Poisson dapat ditulis sebagai berikut (Myers et al.,2010)

$$
Y_{i}=\mu_{i}+\varepsilon_{i}(i=1,2,3, \ldots, n)
$$

dengan $Y_{i}$ adalah jumlah kejadian dan $\mu_{i}$ adalah mean jumlah kejadian dalam periode $t_{i .} \mu_{i}$.

Overdispersi pada data dapat dilihat dari taksiran dispersi yaitu nilai devians dan pearson chi square dibagi nilai derajat bebas bernilai lebih dari satu. Model yang dapat digunakan untuk mengatasi overdispersi di antaranya adalah model ZIGP dan ZIP.

Model ZIP adalah model campuran sederhana untuk data diskret dengan banyak peristiwa nol (Lambert, 1992). Fungsi peluang dari model ZIP adalah sebagai berikut:

$$
\begin{gathered}
P\left(Y_{i}=y_{i}\right)= \\
\left\{\begin{array}{c}
\omega_{i}+\left(1-\omega_{i}\right) e^{-\mu_{i}}, \text { untuk } y_{i}=0 \\
\left(1-\omega_{i}\right) \frac{e^{-\mu_{i} \mu_{i} y_{i}}}{y_{i} !}, \text { untuk } y_{i}=1,2, \ldots ; 0<\omega_{i}<1 .
\end{array}\right.
\end{gathered}
$$

Dari fungsi peluang model regresi ZIP, diperoleh rata-rata dan varians sebagai berikut (Famoye dan Singh, 2006):

$$
\begin{gathered}
E(Y)=\left(1-\omega_{i}\right) \mu, \\
\operatorname{Var}(Y)=\mu(1-\omega)(1+\mu \omega) .
\end{gathered}
$$

berikut:

$\ln (\mu)=X \beta$ dan $\operatorname{logit}(\omega)=\log \left(\frac{\omega}{1-\omega}\right)=X y \cdot(1.5)$

Penaksiran parameter model regresi ZIP dilakukan dengan metode penaksir kemungkinan maksimum (Jansakul \& Hinde,2002). Penaksiran parameter dengan metode penaksir kemungkinan maksimum dihitung dengan memaksimalkan fungsi log likelihoodnya. Penjumlahan fungsi loglikelihood tidak dapat diselesaikan dengan metode numerik biasa, oleh karena itu dapat digunakan algoritma EM (Expectation Maximization).

Pengujian parameter regresi ZIP secara parsial dapat dilakukan dengan dua cara, yaitu pengujian parameter model log dan pengujian parameter model logit. Statistik yang digunakan adalah dengan menggunakan uji Wald (Myers et al., 2010) sebagai berikut:

$$
W=\left(\frac{\widehat{\beta}_{j}}{\operatorname{SE}\left(\widehat{\widehat{\beta}}_{j}\right)}\right)
$$

Untuk kriteria statistik ujinya adalah $H_{0}$ ditolak jika $W>X^{2}{ }_{(d b, \alpha)}$. Pemilihan model terbaik regresi ZIP dapat dilihat dari nilai AIC terkecil (Ismail \&Jemain, 2005).

Regresi zero inflated generalized poisson (ZIGP) merupakan metode untuk menangani overdispersion dengan proporsi data bernilai nol adalah sekitar $65,7 \%$ (Famoye dan Singh, 2006). Model regresi ZIGP sebagai berikut.

$P\left(Y_{i}=y_{i} \mid x_{i}, z_{i}\right)=$ $\left\{\pi_{i}+\left(1-\pi_{i}\right) f\left(\mu_{i}, \omega, y_{i}\right), y_{i}=0\right.$

$\left\{\left(1-\pi_{i}\right) f\left(\mu_{i}, \omega, y_{i}\right) \quad, y_{i}>0\right.$ Dengan $f\left(\mu_{1}, \omega, y_{i}\right), y_{i}=0,1,2, \ldots \quad$ adalah model regresi GP dengan $0<\pi_{i}<1$. Dalam fungsi $\mu_{i}=\mu_{i}\left(x_{i}\right)$ dan $\pi_{i}=\pi_{i}\left(z_{i}\right)$ memenuhi fungsi link sebagai berikut (Famoye dan Singh, 2006).

$$
\log \left(\mu_{i}\right)=\sum_{j=1}^{k} x_{i j} \boldsymbol{\beta}=\boldsymbol{x}^{\boldsymbol{T}} \boldsymbol{\beta}
$$

dan

$$
\operatorname{logit}\left(\pi_{i}\right)=\log \left(\pi_{i}\left[1-\pi_{i}\right]\right)^{-1}=\sum_{j=1}^{m} Z_{i j} \boldsymbol{\delta}
$$

Varians dan mean dari model ZIGP sebagai berikut:

$$
E\left(y_{i} \mid x_{i}\right)=\left(1-\pi_{i}\right) \mu_{i}\left(x_{i}\right)
$$

dan

model hubungan untuk $\mu$ dan $\omega$ adalah sebagai 


$$
\begin{aligned}
\operatorname{Var}\left(y_{i} \mid x_{i}\right)= & \left(1-\pi_{i}\right)\left[\mu_{i}^{2}+\mu_{i}\left(1+\alpha \mu_{i}\right)^{2}\right] \\
& -\left(1-\pi_{i}\right)^{2} \mu_{i}^{2} \\
= & E\left(y_{i} \mid x_{i}\right)\left[\left(1+\alpha \mu_{i}\right)^{2}+\pi_{i} \mu_{i}(1.9)\right.
\end{aligned}
$$

Model regresi ZIGP akan menjadi model regresi GP jika $\pi_{i}=0$ dan akan menjadi model regresi ZIP jika $\omega=0$. Jika matriks kovariat yang sama mempengaruhi $\pi_{i}$ dan $\mu_{i}$ maka dapat ditulis bahwa $\pi_{i}$ adalah fungsi dari $\mu_{i}$ dengan fungsi sebagai berikut.

$\operatorname{logit}\left(\pi_{i}\right)=\log \left(\frac{\pi_{i}}{1-\pi_{i}}\right)=-\tau \sum_{j=1}^{k} x_{i j} \boldsymbol{\beta}=-\tau \boldsymbol{x}^{T} \boldsymbol{\beta}$

Model regresi ZIGP dengan log link untuk $\mu_{i}$ dan untuk logit link untuk $\pi_{i}$ akan dikembangkan dengan $\operatorname{ZIGP}(\tau)$. Jika $\tau>0$ maka kemungkinan zero state terjadi kecil dan jika $\tau<0$ maka kemungkinan zero state terjadi lebih besar. Ketika $\tau=0$ maka model ZIGP $(\tau)$ akan menjadi model $\operatorname{ZIP}(\tau)$.

Penaksir parameter ZIGP digunakan maximum likelihood estimator (MLE) adalah salah satu metode penaksiran parameter yang dapat digunakan untuk menaksir parameter suatu model yang diketahui distribusinya. Metode MLE dilakukan dengan cara memaksimumkan fungsi likelihood. Fungsi likelihood regresi ZIGP sebagai berikut.

$$
=\left\{\begin{array}{c}
\prod_{i=1}^{n} \frac{1}{1+\mu_{i}^{-\tau}}+\left[\mu_{i}^{-\tau}+\exp \left(\frac{-\mu_{i}}{1+\omega \mu_{i}}\right)\right], y_{i}=0 \\
\prod_{i=1}^{n} \frac{1}{1+\mu_{i}^{-\tau}}\left(\frac{-\mu_{i}}{1+\omega \mu_{i}}\right)^{y_{i}} \frac{\left(1+\omega y_{i}\right)^{y^{-1}}}{y_{i}} \exp \left[\frac{-\mu_{i}\left(1+\omega y_{i}\right)}{1+\omega \mu_{i}}\right], y_{i>} 0
\end{array}\right.
$$

Persamaan tersebut dimaksimalkan dengan menggunakan maksimum likelihood untuk koefisien regresi dalam $\widehat{\boldsymbol{\beta}}$. Pada kasus tertentu cara tersebut tidak menghasilkan suatu solusi yang eksplisit sehingga alternatif lain yang dapat digunakan untuk menaksir parameternya adalah dengan algoritma Newton Rapshon. Menurut (Famoye dan Singh, 2006) metode Newton Raphson merupakan metode numerik untuk menyelesaikan persamaan non-linier secara iteratif. Dasar dari model ini adalah pendekatan deret Taylor linier.

Menurut Famoye dan Singh (2006), model regresi ZIGP akan menjadi model regresi ZIP ketika parameter dispersion $\omega=0$. Oleh karena itu untuk melihat kesesuaian model
ZIGP, dilakukan pengujian seperti berikut.

$H_{0}$ : Model ZIGP $(\tau)$ tidak sesuai

$H_{1}$ : Model ZIGP $(\tau)$ sesuai

Untuk mengetahui uji kesesuaian model menggunakan statistik uji sebagai berikut:

$$
D=-2 \ln \left[\frac{L(\widehat{\beta}, \hat{\tau})}{L(\widehat{\beta}, \hat{\tau}, \widehat{\omega})}\right]
$$

Penolakan $H_{0}$ menunjukkan bahwa model regresi ZIP tidak tepat digunakan, sehingga dalam situasi seperti ini model regresi ZIGP lebih tepat digunakan dibandingkan model regresi ZIP.

Pengujian signifikan regresi ZIGP ada dua yaitu pengujian parameter secara serentak dan pengujian secara individu.

\section{Pengujian parameter secara serentak}

Pengujian parameter secara serentak dilakukan untuk mengetahui faktor yang berpengaruh signifikan terhadap model. Berikut ini merupakan hipotesis uji parameter secara serentak model regresi ZIGP.

$H_{0}: \beta_{1}=\beta_{2}=\cdots=\beta_{k}=0$

$H_{1}$ : minimal ada satu paramter $\beta_{k} \neq 0, k$

$$
=1,2, \ldots, k
$$

dengan statistik uji sebagai berikut.

$$
G^{2}=-2 \ln \left(\frac{l_{0}}{l_{1}}\right)
$$

Dengan $l_{0}$ dan $l_{1}$ merupakan lambang maximum log likelihood di bawah $H_{0}$ dan secara keseluruhan $\left(H_{0} \cup H_{1}\right)$. Daerah penolakan pada pengujian parameter secara serentak adalah tolak $H_{0}$ jika $G^{2}>X^{2}{ }_{(p, \alpha)}$ atau jika $P-$ value $<\alpha$.

\section{Pengujian Parameter Secara Individu}

Uji Wald merupakan salah satu pengujian yang dilakukan untuk menguji signifikansi parameter regresi secara individu. Berikut ini merupakan hipotesis uji parameter secara individu model regresi ZIGP.

$$
\begin{aligned}
H_{0}: \beta_{k} & =0 \\
H_{1}: \beta_{k} & \neq 0, k=0,1,2, \ldots, k \\
W & =\frac{\left(\widehat{\beta}_{k}\right)^{2}}{S E\left(\beta_{k}\right)^{2}}
\end{aligned}
$$

Dengan $\hat{\beta}$ merupakan maksimum likelihood estimator parameter $\beta$. Daerah 
penolakan pada pengujian ini adalah tolak $H_{0}$ jika $W_{\text {hitung }}>X_{(1, \alpha)}^{2}$ atau Pvalue $<\alpha$.

Pemilihan model terbaik (Goodness of Fit) Salah satu pemilihan model terbaik adalah dengan metode Akaike's Information Criterion (AIC). Nilai AIC dapat dihitung dengan menggunakan rumus berikut.

AIC (Akaike's information Criterion)

$$
A I C=-2 \log L(\hat{\beta})+2 k
$$

Dengan $L(\hat{\beta})$ merupakan nilai likelihood dan $k$ merupakan jumlah parameter. Kriteria pemilihan model terbaik jika didapatkan nilai terkecil atau mendekati nol (Ismail \& Jemain, 2005).

\section{METODE PENELITIAN}

Jenis dan sumber data Penelitian ini menggunakan data Angka Kematian Ibu Hamil pada tahun 2016. Data yang digunakan dalam penelitian ini merupakan data sekunder yang diperoleh dari Dinas Kesehatan Provinsi Bali dari seluruh Kabupaten/kota di Provinsi Bali yang telah terbagi menjadi 57 Kecamatan di Provinsi Bali.

Variabel yang digunakan pada penelitian ini adalah jumlah kematian ibu hamil (Y), Persentase ibu hamil yang melaksanakan kunjungan $\mathrm{K} 1\left(X_{1}\right)$, Persentase ibu hamil yang melaksanakan kunjungan $\mathrm{K} 4\left(X_{2}\right)$, Persentase ibu hamil yang mendapatkan tablet tambahan darah $\operatorname{Fe} 1\left(X_{3}\right)$, Persentase ibu hamil yang mendapatkan tablet tambahan darah $\mathrm{Fe} 3\left(X_{4}\right)$, Persentase ibu hamil mendapatkan imunisasi $\operatorname{TT5}\left(X_{5}\right)$. Berikut adalah langkah-langkah yang dilakukan untuk mencapai tujuan dalam penelitian ini.

1. Melakukan pengumpulan dan penyajian data, serta mendeskripsikan data penelitian menggunakan statistik deskritif.

2. Melakukan uji overdispersi. Uji overdispersi pada data dapat diukur dengan taksiran dispersi, apabila nilai devians dan pearson chi-square dibagi dengan derajat bebasnya bernilai lebih dari 1 , maka data mengalami overdispersi. Jika data mengalami overdispersi maka dilanjutkan dengan langkah 3. Namun jika data tidak mengalami overdispersi maka data dapat dianalisis menggunakan regresi Poisson.

3. Menaksir parameter model regresi ZIGP . Untuk menaksir parameter pada regresi ZIGP menggunakan algoritma NewtonRaphson.

4. Melakukan uji kesesuaian model regresi ZIGP. Menentukan apakah model yang diperoleh sesuai atau tidak dengan model regresi ZIGP. Dengan hipotesis-hipotesis sebagai berikut

$H_{0}$ : Model ZIGP $(\tau)$ tidak sesuai

$H_{1}$ :ModelZIGP $(\tau)$ sesuai

5. Melakukan uji signifikan pada model regresi ZIGP, dengan menggunakan uji parameter secara secara serentak dan pengujian parameter secara individu.

6. Menentukan model terbaik dari regresi ZIGP dengan menggunakan model Akaikes's Information Criterion (AIC), $A I C=-2 \log L(\hat{\beta})+2 k$.

Langkah-langkah tersebut dapat dibantu dengan menggunakan software Minitab 17 dan Software RStudio.

\section{HASIL DAN PEMBAHASAN}

\subsection{Deskripsi data}

Deskripsi jumlah kematian ibu hamil (Y) memiliki nilai minimum 0 , nilai maksimum 3 , dan banyaknya pengamatan adalah 57. Jumlah total kematian ibu hamil pada tahun 2016 sebanyak 18 orang. Jumlah data yang bernilai nol (tidak ada ibu hamil yang meninggal) sebanyak 46 Kecamatan. Terdapat faktor-faktor yang diduga memengaruhi kasus Kematian Ibu Hamil di Provinsi Bali yaitu Deskripsi data pada variabel bebasnya dapat dilihat dari Tabel 1

Tabel 1. Deskripsi Data Variabel Bebas

$$
\left(X_{1}, X_{2}, X_{3}, X_{4}, X_{5}\right)
$$

\begin{tabular}{|l|l|l|l|l|}
\hline $\begin{array}{l}\text { Variabel } \\
\text { bebas }\end{array}$ & Min & Maks & $\begin{array}{l}\text { Rata- } \\
\text { rata }\end{array}$ & Varians \\
\hline X1 & $70,0 \%$ & $100 \%$ & $91,54 \%$ & $55,70 \%$ \\
\hline X2 & $70,30 \%$ & $100 \%$ & $89,06 \%$ & $93,37 \%$ \\
\hline X3 & $64,50 \%$ & $100 \%$ & $93,21 \%$ & $67,27 \%$ \\
\hline X4 & $62,60 \%$ & $100 \%$ & $90,83 \%$ & $71,07 \%$ \\
\hline X5 & $25,20 \%$ & $100 \%$ & $70,58 \%$ & $423,01 \%$ \\
\hline
\end{tabular}

Sumber: data diolah (2018) 
Berdasarkan statistik deskritif pada Tabel 1. Berturut-turut diperoleh nilai rata-rata ibu yang melakukan kunjungan $\mathrm{K} 1, \mathrm{~K} 4$, mendapatkan tablet tambah darah $\mathrm{Fe} 1, \mathrm{Fe} 3$ dan ibu mendapatkan imunisasi TT5 yaitu sebesar $91,54 \%, 89,06 \%, 93,21 \%, 90,83 \%$, dan $70,58 \%$ yang menunjukkan sebagian besar ibu hamil di provinsi Bali telah melaksanakan kunjungan K1, K4, mendapatkan tablet tambah darah Fe1, Fe3 dan ibu mendapatkan imunisasi TT5. Di sisi lain, nilai varians yang mendekati $100 \%$ menunjukkan bahwa terdapat perbedaan yang signifikan antara nilai rata-rata dan banyaknya ibu hamil yang melaksanakan kujungan K1, K4, mendapatkan tablet tambah darah $\mathrm{Fe} 1, \mathrm{Fe} 3$ dan ibu mendapatkan imunisasi TT5. Hal ini menunjukkan ketimpangan yang cukup signifikan antar Kecamatan di provinsi Bali dalam hal ibu hamil yang melakukan kunjungan $\mathrm{K} 1, \mathrm{~K} 4$, mendapatkan tablet tambah darah $\mathrm{Fe} 1, \mathrm{Fe} 3$ dan ibu mendapatkan imunisasi TT5.

Nilai varians tertinggi sebesar $93,21 \%$ yaitu ibu hamil melaksanakan kunjungan $\mathrm{K} 4\left(X_{2}\right)$ menunjukkan bahwa ketimpangan tertinggi dari nilai rata-rata terjadi pada ibu hamil yang melakukan kunjungan K4. Hal ini berarti sebagian besar Kecamatan di Provinsi Bali dengan ibu hamil yang melakukan kunjungan K4 jauh dari nilai rata-rata $89,06 \%$.

Menurut penelitian Fitrayeni (2015) dalam skripsi Indrian (2012) yang menyatakan tinggi rendahnya ibu hamil melaksanakan kunjungan $\mathrm{K} 1, \mathrm{~K} 4$, mendapatkan tablet tambah darah Fe1, $\mathrm{Fe} 3$ dan ibu mendapatkan imunisasi TT5 dipengaruhi oleh faktor status ekonomi, tingkat pendidikan, dukungan keluarga dan sulitnya akses terhadap pelayanan kesehatan.

\subsection{Pemeriksaan Uji Overdispersi}

Taksiran dispersi diukur dari nilai devians dan nilai pearson chi-square dibagi derajat bebas bernilai lebih dari satu. Data jumlah kematian ibu hamil di Provinsi Bali tahun 2016 memiliki nilai devians dibagi derajat bebasnya sebesar 1,106269 dan nilai pearson chi square dibagi derajat bebasnya sebesar 1,440812.
Hasil tersebut menunjukkan nilai devians dan pearson chi square yang dibagi derajat bebasnya bernilai lebih besar dari satu, sehingga disimpulkan data mengalami overdispersi.

\subsection{Model Regresi Zero Inflated Generalized Poisson (ZIGP)}

Pada kasus kematian ibu hamil variabel bebasnya yaitu persentase ibu hamil melaksanakan kunjungan $\mathrm{K} 1\left(X_{1}\right)$, persentase ibu hamil melaksanakan kunjungan $\mathrm{K} 4\left(X_{2}\right)$, Persentase ibu hamil yang mendapatkan tablet tambahan darah Fe1 $\left(X_{3}\right)$, Persentase ibu hamil yang mendapatkan tablet tambahan darah $\mathrm{Fe} 3$ $\left(X_{4}\right)$, dan Persentase ibu hamil mendapatkan imunisasi TT5 $\left(X_{5}\right)$.

Sebelum membuat model, maka perlu dilakukan penaksiran parameter, pengujian kesesuaian model, dan pengujian parameter secara serentak dan secara individu. Estimasi parameter model regresi zero inflated generalized Poisson dengan bantuan software RStudio dapat dilihat pada Tabel 2.

Berdasarkan Tabel 2. dapat dilihat bahwa hasil analisis regresi Zero Inflated Generalized Poisson (ZIGP) menunjukkan bahwa tidak ada variabel yang signifikan terhadap tingkat kematian ibu hamil, sehingga ada indikasi model ZIGP tidak sesuai. Langkah selanjutnya dilakukan pengujian kesesuain model ZIGP.

\subsection{Pengujian Kesesuaian Model ZIGP}

Untuk menguji kecocokan regresi Zero Inflated Generalized Poisson (ZIGP) dengan data, digunakan statistik uji Devians dan Pearson chi-square dengan hipotesis sebagai berikut:

$$
\begin{aligned}
& H_{0} \text { : Model ZIGP }(\tau) \text { tidak sesuai } \\
& H_{1} \text { : Model ZIGP }(\tau) \text { sesuai. }
\end{aligned}
$$

Tingkat signifikan yang digunakan adalah 0,05 , $H_{0}$ akan ditolak jika nilai devians lebih besar dari tabel chi-square $\left(D>\chi_{(0,05 ; 51)}^{2}=\right.$ $68,67)$. 
Table 2. Nilai Estimasi Parameter Model Regresi Zero Inflated Generalized Poisson dengan Seluruh Variabel Bebas

\begin{tabular}{|c|l|c|c|c|}
\hline Koefisien & Variabel & $\begin{array}{l}\text { Estimasi } \\
\text { Parameter }\end{array}$ & $\mathrm{z}$ value & P-value \\
\hline$\beta_{0}$ & Intercept & 8,16329 & 1,9984 & 0,0457 \\
\hline$\beta_{1}$ & $\begin{array}{l}\text { Kunjungan } \\
\text { K1 }\end{array}$ & $-0,06456$ & $\begin{array}{c}- \\
1,7855\end{array}$ & 0,0742 \\
\hline$\beta_{2}$ & $\begin{array}{l}\text { Kunjungan } \\
\text { K4 }\end{array}$ & $-0,02924$ & $\begin{array}{c}- \\
0,8637\end{array}$ & 0,3877 \\
\hline$\beta_{3}$ & $\begin{array}{l}\text { Tambah } \\
\text { Darah Fe1 }\end{array}$ & $-0,02133$ & $\begin{array}{c}- \\
0,3481\end{array}$ & 0,7278 \\
\hline$\beta_{4}$ & $\begin{array}{l}\text { Tambah } \\
\text { Darah Fe3 }\end{array}$ & $-0,00304$ & 0,0523 & 0,9583 \\
\hline$\beta_{5}$ & $\begin{array}{l}\text { Imunisasi } \\
\text { TT5 }\end{array}$ & 0,01573 & 0,9504 & 0,3419 \\
\hline $\begin{array}{l}\text { Log- } \\
\text { likelihood }\end{array}$ & $\begin{array}{l}\text { Log- } \\
\text { likelihood }\end{array}$ & $-36,1$ & & \\
\hline AIC & AIC & 86 & & \\
\hline Omega & Omega & 0,00000 & & \\
\hline Sumber: & da diolah & & \\
\hline
\end{tabular}

Sumber: data diolah (2018)

Berdasarkan luaran software Rstudio diperoleh devians nilai devians $(D)=$ $61,95108<68,67$, sehingga terima $H_{0}$ Oleh karena itu model ZIGP tidak sesuai. Dengan demikian model ZIGP akan menjadi model Zero Inflated Poisson (ZIP) (Famoye and Singh, 2006).

\subsection{Analisis Regresi Zero Inflated Poisson (ZIP)}

Berdasarkan analisis regresi Zero Inflated Generalized Poisson (ZIGP) disimpulkan bahwa data jumlah kematian ibu hamil $(Y)$ tidak dapat dimodelkan dengan menggunakan model regresi Zero Inflated Generalized Poisson (ZIGP). Dengan demikian model ZIGP akan tereduksi menjadi model Zero Inflated Poisson (ZIP). Analisis regresi Zero Inflated Poisson (ZIP) dapat digunakan untuk menangani kasus zero inflation pada regresi Poisson jika asumsi overdispersi tidak terpenuhi. Langkah selanjutnya adalah menganalisis model regresi ZIP dengan bantuan software Rstudio.

Analisis regresi dengan ZIP akan menghasilkan dua model yakni count model untuk memprediksi data cacah dan zero inflated model untuk memprediksi probabilitas terjadinya zero response pada data. Pemodelan regresi ZIP pada kasus kematian ibu hamil di- lakukan dengan memodelkan dari keseluruhan kombinasi variabel bebas dan dari modelmodel tersebut dipilih model yang signifikan dan memiliki nilai AIC terkecil.

Berdasarkan hasil seluruh kombinasi model dari variabel bebas diperoleh model yang memiliki AIC yang paling kecil. Model terbaik yang digunakan ditentukan dengan mempertimbangkan model yang signifikan dan memiliki AIC terkecil. berikut hasil estimasi parameter model regresi ZIP dengan bantuan software Rstudio pada Tabel 3.

Tabel 3. Estimasi Parameter Model Regresi ZIP

\begin{tabular}{|l|l|l|l|l|}
\hline Variabel & Estimasi & $\begin{array}{l}\text { Standar } \\
\text { Error }\end{array}$ & $z$ value & P-value \\
\hline Count model & $-3,61284$ & 3,46884 & $-1,042$ & 0,298 \\
\hline Intercept & $-0,04217$ & 0,04038 & 1,044 & 0,029 \\
\hline K1(X1) & -54 & \\
\hline Zero inflated model \\
\hline Intercept & $-26,5558$ & 13,9174 & $-1,908$ & 0,056 \\
\hline K1(X1) & $-0,3021$ & 0,1562 & 2,011 & 0,044 \\
\hline $\begin{array}{l}\text { Log } \\
\text { likelihood }\end{array}$ & $-33,57$ & & & \\
\hline AIC & 75,13 & & & \\
\hline
\end{tabular}

Sumber: data diolah (2018)

Berdasarkan Tabel 3. dapat disimpulkan bahwa kematian ibu hamil pada count model dan zero inflated dipengaruhi oleh variabel cakupan pemeriksaan kehamilan $\mathrm{K} 1 X_{1}$ yang berpengaruh signifikan. Model regresi ZIP pada kasus kematian ibu hamil menghasilkan nilai log-likelihood -33,57. model log dan logit regresi ZIP pada kasus kematian ibu hamil diatas dituliskan sebagai berikut.

$$
\begin{gathered}
\log \left(\mu_{i}\right)=-3,61284-0,04217 X 1 \\
\mu_{i}=\exp (-3,61284-0,04217 K 1) \\
\operatorname{logit}(\omega)=\exp (-26,5558-0,3021 \mathrm{X} 1) \\
\omega=(-26,5558-0,3021 \mathrm{~K} 1)
\end{gathered}
$$
dan

dengan $X_{1}$ adalah presentase ibu melaksanakan kunjungan $\mathrm{K} 1$. Iinterpretasi model yang terbentuk dari analisis regresi ZIP didasarkan pada nilai ood rasio dari masing-masing koefisien yang terlihat dari nilai $\exp (\hat{\beta})$.Nilai koefisien regresi $(\hat{\beta})$ beserta nilai $\exp (\hat{\beta})$ untuk model $\ln (\mu)$ dapat dilihat pada Tabel 4 . 
Tabel 4. Nilai Koefisien Regresi $(\hat{\beta})$ beserta nilai $\exp (\hat{\beta})$ model $\ln (\mu)$

\begin{tabular}{|c|c|c|}
\hline Variabel bebas & Koefisien $(\hat{\beta})$ & $\exp (\hat{\beta})$ \\
\hline Intercept & $-3,61284$ & 0,0269 \\
\hline$X_{1}$ & $-0,04217$ & 0,9587 \\
\hline
\end{tabular}

Sumber: data diolah (2018)

Interpretasi dari nilai ood rasio variabel $X_{1}$ adalah hasil penelitian menunjukkan koefisien regresinya bernilai negatif, maka untuk setiap peningkatan $1 \%$ cakupan melaksanakan kunjungan K1 di satu Kecamatan di Provinsi Bali akan mengurangi rata-rata jumlah kematian ibu hamil sebesar 4,13\%. Pengurangan sebesar4,13\% pada rata-rata jumlah kematian ibu hamil karena terjadinya peningkatan $1 \%$ ibu yang melaksanakan kunjungan didasarkan pada perhitungan berikut.

$$
\begin{gathered}
100\left(e^{0,9587(1)}-1\right) \%=100(0,9587-1) \% \\
=-4,13 \%
\end{gathered}
$$

Nilai koefisien regresi $(\hat{y})$ beserta nilai $\exp (\hat{y})$ untuk model logit $(\omega)$ dapat dilihat pada Tabel 5.

Tabel 5. Nilai Koefisien Regresi $(\hat{y})$ beserta Nilai $\exp (\hat{y})$ Model logit $(\omega)$

\begin{tabular}{|l|l|c|}
\hline $\begin{array}{l}\text { Variabel } \\
\text { Bebas }\end{array}$ & Koefisien $(\hat{y})$ & $\exp (\hat{y})$ \\
\hline Intercept & $-26,5558$ & $2,93 \times 10^{-12}$ \\
\hline$X_{1}$ & $-0,3021$ & 0,7392 \\
\hline
\end{tabular}

Sumber: data diolah (2018)

Interpretasi dari nilai ood rasio adalah hasil penelitian menunjukkan bahwa koefisien regresinya bernilai negatif, maka untuk setiap peningkatan $1 \%$ ibu yang melaksanakan kunjungan akan mengurangi probabilitas jumlah kematian ibu sebesar $26,08 \%$. Pengurangan sebesar 26,08\% pada probabilitas jumlah kematian ibu hamil karena terjadinya peningkatan $1 \%$ ibu yang melaksanakan kunjungan didasarkan pada perhitungan berikut:

$$
\begin{gathered}
100\left(e^{0,7392(1)}-1\right) \%=100(0,7392-1) \% \\
=-26.08 \%
\end{gathered}
$$

\section{KESIMPULAN DAN SARAN}

Berdasarkan hasil dan pembahasan maka dapat diambil kesimpulan sebagai berikut:

1. Dari hasil analisis model regresi ZIGP diperoleh bahwa hasil analisis model regresi ZIGP tidak sesuai untuk memodelkan data angka kematian ibu hamil di Provinsi Bali. Dengan demikian angka kematian ibu hamil di Provinsi Bali dianalisis menggunakan metode regresi ZIP.

Dari hasil analisis ZIP diperoleh model terbaik sebagai berikut:

$$
\begin{aligned}
\log \left(\mu_{i}\right) & =-3,61284-0,04217 X 1 \\
\operatorname{logit}(\omega) & =\exp (-26,5558-0,3021 \mathrm{X} 1)
\end{aligned}
$$

2. Berdasarkan kriteria nilai AIC terkecil pada model ZIP maka faktor yang mempengaruhi kematian ibu hamil yaitu ibu melaksanakan kunjungan (K1).

Hal-hal yang disarankan peneliti berdasarkan penelitian jumlah kematian ibu hamil di Provinsi Bali adalah penelitian selanjutnya dapat membandingkan model regresi Zero Inflated Generalized Poisson (ZIGP) dengan model regresi Zero Inflated Negative Binomial Poisson (ZINB).

\section{DAFTAR PUSTAKA}

Dinas Kesehatan Provinsi Bali. 2016. Profil Kesehatan Provinsi Bali Tahun 2016. Bali: Dinkes Provinsi Bali.

Famoye, F. dan Singh, K. P., (2006), Zero Inflated Generalized Poisson Regression Model with an Application to Domestic Violence Data, Journal of Data Science,4, hal.117-130.

Ismail, N. \& A.A. Jemain. 2005. Generalized Poisson Regression: An Alternative For Risk Classification. Jurnal Teknologi. Vol. 43, No.1, 39-50

Jansakul, N \& J.P. Hinde. 2002. Score Tests for Zero-Inflated Poisson Models. Computational Statistics \& Data Analysis. Vol.40, No.1,75-96.

Lambert, D. 1992. Zero Inflated Poisson Regression, with an Application to Detect in Manufacturing. Technometrics. Vol.34, No.1, 1-14. 
McCullagh, p. \& Nelder, J. A. 1989.

Generalized Linier Models. Second edition.

London: Chapman and Hall

Myers, R.H., Douglas C. Montgomery, G.

Geoffrey Vinning, \&Timothy J,

Robinson.2010. Generalized Linier Models with Application in Engineering and The

Sciences. Second edition. New Jersey: John Wiley and Sons.

Indrian Dini, Lisa. 2012. Faktor-Faktor Yang Berhubungan Dengan Pemanfaatan Pelayanan Antenatal Care Oleh Ibu Hamil Di Wilayah Kerja Puskesmas Baserah Kab. Kuansing Propinsi Riau Tahun 2012 [Skripsi] Padang. FKM UNAND. 2012 